\title{
Produção de metabólitos bioativos pelo líquen Cladonia substellata Vainio ${ }^{1}$
}

\author{
Sheyla Mara Ribeiro ${ }^{2,6}$, Eugênia Cristina Pereira ${ }^{3}$, Norma Buarque Gusmão ${ }^{4}$, Emerson Peter Falcão ${ }^{5}$ e \\ Nicácio Henrique da Silva ${ }^{5}$
}

\author{
Recebido em 9/11/2004. Aceito em 31/08/2005
}

\begin{abstract}
RESUMO - (Produção de metabólitos bioativos pelo líquen Cladonia substellata Vainio). Objetivando comparar a atividade antimicrobiana de extratos brutos de Cladonia substellata, proveniente dos Estados de Minas Gerais e Pará, Brasil, utilizou-se o método de difusão em meio sólido. Extratos etéreo, clorofórmico e acetônico foram testados contra patógenos humanos e fitopatógenos na concentração de $1,0 \mathrm{mg} / \mathrm{mL}, 0,1 \mathrm{mg} / \mathrm{mL}$ e $0,01 \mathrm{mg} / \mathrm{mL}$. Os extratos foram submetidos à cromatografia em camada delgada, e o princípio ativo atribuído através de biocromatografia. Os resultados demonstraram que as sete espécies de fungos testadas foram resistentes aos extratos de C. substellata procedente do Pará, porém, quatro destas espécies mostraram-se sensíveis aos extratos etéreo e clorofórmico da amostra de Minas Gerais. Todos os extratos foram ativos contra as mesmas espécies de bactérias, entretanto os extratos da amostra procedente de Minas Gerais demonstraram melhor atividade. Das bactérias inibidas, Staphylococcus aureus mostrou-se a menos sensível, ao contrário das fitopatógenas que apresentaram grande sensibilidade. Os testes cromatográficos revelaram a presença de ácido úsnico em todos os extratos, porém, em maior quantidade na amostra do Pará. O biocromatograma revelou este ácido como princípio ativo da espécie, além de sua ação sinérgica com o ácido norestíctico, na amostra de Minas Gerais, justificando sua maior atividade.
\end{abstract}

Palavras-chave: Cladonia substellata, ácido úsnico, ácido norestíctico, atividade antimicrobiana

\begin{abstract}
Production of bioactive metabolites from lichen Cladonia substellata Vainio). This work purposed to make a comparison between antimicrobial activity of crude extracts from Cladonia substellata, collected at Minas Gerais and Pará States, Brazil, using the diffusion solid medium methods. Ether, chloroform, and acetone extracts, at $1 \mathrm{mg} / \mathrm{mL}, 0.1 \mathrm{mg} / \mathrm{mL}$, and $0.01 \mathrm{mg} / \mathrm{mL}$, were tested against human pathogens and phytopathogens. The extracts were submitted to thin layer chromatography and their active principles attributed by biochromatography. The results demonstrated that the seven fungi species tested were no sensitive to extracts from C. substellata from Pará. On the other hand, four of these microorganisms were inhibited by C. substellata extracts from Minas Gerais. All extracts were active to the same bacteria species, but samples from Minas Gerais showed the highest activity. Among the inhibited bacteria Staphylococcus aureus was the less sensitive, with an opposite behavior to phytopathogen ones, that showed the highest sensitivity. Chromatographic assays revealed the presence of usnic acid in all extracts, thus in the most content in Pará samples. The biochromatograms reveals usnic acid as active principle of the species, and a synergic action to norstictic acid found in Minas Gerais samples, what justify its highest activity.
\end{abstract}

Key words: Cladonia substellata, usnic acid, norstictic acid, antimicrobial activity

\section{Introdução}

Liquens produzem substâncias com propriedade antibiótica, que podem variar qualitativa e quantitativamente em uma mesma espécie, dependendo das condições ambientais. Segundo Hale (1983), variações de temperatura, umidade e luminosidade podem interferir na atividade fisiológica dos liquens, afetando a síntese de seus metabólitos.
Culberson et al. (1983) observaram que o efeito da temperatura, e de outros fatores ambientais, variava de acordo com a substância analisada, pois enquanto o ácido barbático em Cladonia cristatella diminuia significativamente com o aumento da temperatura, os níveis de dibenzofuranos permaneciam praticamente constantes. Em 1985, Huovinen concluiu que a quantidade de ácido perlatólico em Cladina stellaris e ácido

1 Parte da Dissertação de Mestrado da primeira Autora

2 Universidade Federal do Acre, Departamento de Ciências da Saúde, Campus Universitário, Km 04, CEP 69915-900, Rio Branco, AC, Brasil

3 Universidade Federal de Pernambuco, Centro de Filosofia e Ciências Humanas, Departamento de Ciências Geográficas

4 Universidade Federal de Pernambuco, Centro de Ciências Biológicas, Departamento de Antibióticos

5 Universidade Federal de Pernambuco, Centro de Ciências Biológicas, Departamento de Bioquímica

6 Autor para correspondência: sheylaribeiro@ hotmail.com 
fumarprotocetrárico em Cladina rangiferina variava de acordo com a localização geográfica das espécies, ao observar que a quantidade de ambos os compostos diminuia em regiões mais frias da Finlândia e Noruega.

A ação antimicrobiana dos metabólitos liquênicos tem sido estudada desde 1944 por Burkholder e colaboradores, e desde então várias substâncias foram identificadas como agentes antibióticos, sendo sua ação bacteriostática e bactericida comprovada principalmente contra bactérias Gram positivas (Bustinza 1951). As substâncias ativas são em geral depsídeos, depsidonas e ácidos úsnicos, dentre outras classes de compostos, alguns ainda não identificados (Fahselt 1994; Huneck 1999; Muller 2001).

Pereira et al. (1997) constataram diferenças na atividade antimicrobiana de liquens coletados em um mesmo local, em diferentes estações do ano, e afirmou que durante o período seco eles produzem e armazenam maior quantidade de compostos ativos. É provável que as substâncias contidas no talo sejam lixiviadas durante o período chuvoso, enquanto, no período seco, ocorre um acúmulo dessas substâncias no talo liquênico, o que justifica sua maior atividade.

Variações na produção de substâncias liquênicas são comuns tanto em uma mesma espécie submetida a diferentes condições ambientais, como também entre exemplares de uma espécie submetidos às mesmas condições locais. Alguns estudos relatam que, além das condições ambientais, outros fatores podem influenciar na produção de metabólitos liquênicos, como por exemplo, a idade do talo e fatores genéticos (Quilhot \& Guzmán 1988; Ahti 2000).

Ahti (2000) relatou a ocorrência de amostras de Cladonia substellata com composição química diferente, não só em localidades distintas, mas também co-habitando em uma mesma localidade, demonstrando, mais uma vez, que apesar da influência de fatores ambientais na composição química dos liquens, podem ocorrer variações em uma mesma espécie independente destes fatores. Isto levou o referido autor a sugerir pelo menos três quimiotipos distintos para C. substellata.

Alguns trabalhos, como os de Pereira et al. (1991; 1996), atribuem a ação antimicrobiana de C. substellata ao ácido úsnico, composto geralmente encontrado em abundância nesta espécie. Porém, em um estudo sobre a família Cladoniaceae, Ahti (2000) detectou ausência deste composto em dois exemplares de $C$. substellata, provenientes da Serra de Ibitipoca, Minas Gerais, Brasil.
Face ao exposto, o presente trabalho objetivou comparar a composição química e a atividade antimicrobiana de duas amostras de C. substellata, provenientes de diferentes localidades do Brasil.

\section{Material e métodos}

Material liquênico - Foram utilizadas duas amostras de Cladonia substellata Vainio. Uma foi coletada em campo rupestre, sobre substrato rochoso, na Serra do Caraça, município de Catas Altas - Minas Gerais, em setembro/1997; a outra foi coletada em ambiente de campina, sobre solo arenoso, no Povoado do Guajará, município do Acará - Pará, em janeiro/1998. As amostras foram acondicionadas em sacos de papel e conduzidas ao laboratório, onde foram secas à temperatura ambiente $\left(25 \pm 3{ }^{\circ} \mathrm{C}\right)$. Posteriormente, foram identificadas, por meio de caracteres morfológicos e químicos do talo, e depositadas no Herbário UFP da Universidade Federal de Pernambuco (UFPE), sob os seguintes números de registro: n. 28.291 (amostra procedente de Minas Gerais) e n. 28.292 (amostra procedente do Pará).

Preparação dos extratos - A partir de $20 \mathrm{~g}$ do talo liquênico seco, foram obtidos extratos orgânicos por sistema de esgotamento a frio, seguindo a série eluotrópica éter, clorofórmio e acetona. O material foi triturado em almofariz e extraído com $100 \mathrm{~mL}$ de éter etílico em agitação por $1 \mathrm{~h}$, sendo em seguida mantido em repouso por $24 \mathrm{~h}$ a $6{ }^{\circ} \mathrm{C}$. Após esse período, o material foi filtrado e o resíduo extraído com o mesmo volume de clorofórmio. Em seguida, após filtração, o resíduo foi novamente extraído com acetona, sob as mesmas condições. Os extratos foram evaporados à temperatura ambiente e mantidos em dessecador até peso constante.

Microrganismos teste - Os testes de atividade antifúngica foram realizados com Trichophyton tonsurans, T. rubrum, T. mentagrophytes, T. shoenlynii, Epidermophyton floccosum, Microsporum canis, e duas cepas de Candida albicans (isolados clínicos n. 6307 e n. 6370), cedidos pelo Departamento de Micologia da UFPE. Para os testes de atividade antibacteriana foram utilizadas cepas de Staphylococcus aureus (DAUFPE - 01), Bacillus subtilis (DAUFPE - 16), Pseudomonas aeruginosa (DAUFPE - 39), Escherichia coli (DAUFPE - 224) e Klebsiella pneumoniae (DAUFPE - 396), como representantes de bactérias Gram positivas e Gram negativas patógenas ao homem, cedidas pelo 
Departamento de Antibióticos da UFPE. Além destas, foram testadas cepas de Ralstonia solanacearum bv. I (A-2.4), R. solanacearum bv. III (RC-40), Xanthomonas campestris pv. campestris (isolados recentes de culturas de repolho ) e X. campestris pv. vesicatoria (isolados recentes de culturas de tomate), como representantes de bactérias Gram negativas fitopatógenas, cedidas pelo Laboratório de Fitossanidade da Universidade Federal Rural de Pernambuco (UFRPE).

Testes antimicrobianos - Os ensaios de atividade antimicrobiana foram realizados pelo método de difusão em meio sólido, segundo Grove \& Randall (1955). Alíquotas de $50 \mathrm{~mL}$ das suspensões de microrganismos a $10^{7} \mathrm{UFC} / \mathrm{mL}$, padronizadas pelo método de Bauer et al. (1966), foram inoculadas em placas de Petri com $9,0 \mathrm{~cm}$ de diâmetro, contendo $15 \mathrm{~mL}$ de meio específico para cada tipo de microrganismo. Os testes de atividade antifúngica foram desenvolvidos em meio ágar Sabouraud e os ensaios antibacterianos em meio ágar Mueller-Hinton, para patógenos humanos, e ágar Nutritivo Dextrose Levedura, para fitopatógenos.

Discos de papel xarope com $6 \mathrm{~mm}$ de diâmetro foram impregnados com $25 \mu \mathrm{L}$ de cada extrato liquênico nas concentrações de $1 \mathrm{mg} / \mathrm{mL}, 0,1 \mathrm{mg} / \mathrm{mL}$ e $0,01 \mathrm{mg} / \mathrm{mL}$, sendo, em seguida, depositados sobre o meio previamente inoculado. Como controle de uma possível interferência dos solventes no processo de inibição, utilizaram-se discos impregnados com os respectivos solventes utilizados para extração. O experimento foi realizado em triplicata.

As placas de Petri foram incubadas a $30{ }^{\circ} \mathrm{C}$ para fungos filamentosos, leveduras e bactérias fitopatógenas, e a $37^{\circ} \mathrm{C}$ para bactérias patógenas ao homem. Os resultados foram avaliados mediante formação e dimensão dos halos de inibição em volta dos discos, em $24 \mathrm{~h}$ de crescimento para bactérias e leveduras e em $72 \mathrm{~h}$ para fungos filamentosos. Os resultados foram expressos pela média das três repetições.

Cromatografia em camada delgada (CCD) - Os extratos etéreo, clorofórmico e acetônico de ambas as amostras foram submetidos à cromatografia ascendente em placas de sílica Gel $60 \mathrm{~F}_{254+366}$ (Merck) com $20 \times 20 \mathrm{~cm}$, sendo desenvolvidas nos sistemas de solventes A (tolueno/ dioxano/ácido acético, 180:45:5 v/v) e B (hexano/éter etílico/ácido fórmico, 130:80:20 v/v), segundo Culberson (1972). As bandas obtidas foram visualizadas sob luz ultravioleta (UV) a $254 \mathrm{~nm}$ e $366 \mathrm{~nm}$.

As cromatoplacas foram reveladas com $\mathrm{H}_{2} \mathrm{SO}_{4}$ a $10 \%$ e aquecidas a $100{ }^{\circ} \mathrm{C}$ por $10 \mathrm{~min}$. As bandas evidenciadas foram comparadas por meio de reação de coloração e valores de Rf (Fator de Retenção), com os padrões de ácidos úsnico, estíctico e norestíctico aplicados como referência.

Biocromatografia - $\mathrm{O}$ teste biocromatográfico foi realizado seguindo o método de Homans \& Fuchs (1970). Alíquotas de $50 \mathrm{~mL}$ dos extratos liquênicos mais ativos contra os microrganismos testados, foram cromatografadas na concentração de $1 \mathrm{mg} / \mathrm{mL}$, como descrito no item anterior, sendo utilizada uma placa cromatográfica com $10 \times 10 \mathrm{~cm}$. Em seguida, a cromatoplaca foi depositada em uma placa de Petri com $18 \mathrm{~cm}$ de diâmetro, e sobre ela $30 \mathrm{~mL}$ de meio específico inoculado com o microrganismo mais sensível nos testes antimicrobianos.

A placa foi incubada de acordo com o microrganismo utilizado, e os resultados avaliados mediante formação de halo de inibição em volta da banda cromatográfica correspondente à substância ativa dos extratos testados.

\section{Resultados e discussão}

Os testes cromatográficos revelaram variações na composição química das amostras de Cladonia substellata, provenientes de diferentes localidades do Brasil. A CCD desenvolvida no sistema de solventes A revelou a presença de cinco bandas nos extratos etéreo, clorofórmico e acetônico da amostra proveniente de Minas Gerais (MG) e três na amostra do Pará (PA). As bandas com Rf igual a 0,84, 0,53 e 0,10 apresentaram reação de coloração e valores de Rf semelhantes aos dos padrões de ácidos úsnico, norestíctico e estíctico, respectivamente. Porém, duas bandas de cada amostra não puderam ser identificadas por não coincidirem com nenhum dos padrões aplicados como referência (Fig. 1A). No sistema B observou-se três bandas em cada extrato de ambas as amostras, sendo identificados os ácidos úsnico, norestíctico e estíctico, com valores de Rf igual a 0,68, 0,36 e 0,12, respectivamente (Fig. 1B).

Esses dados estão de acordo com Huovinen \& Ahti (1986) que reportaram os ácidos úsnico, norestíctico e estíctico para $C$. substellata de Minas Gerais, Brasil. Outros compostos, como os ácidos conorestíctico, criptoestíctico e conestíctico também são citados para esta espécie, por autores como Ahti et al. (1993) e Pereira et al. (1996), porém, seus valores de Rf são muito diferentes das substâncias encontradas no presente trabalho. 


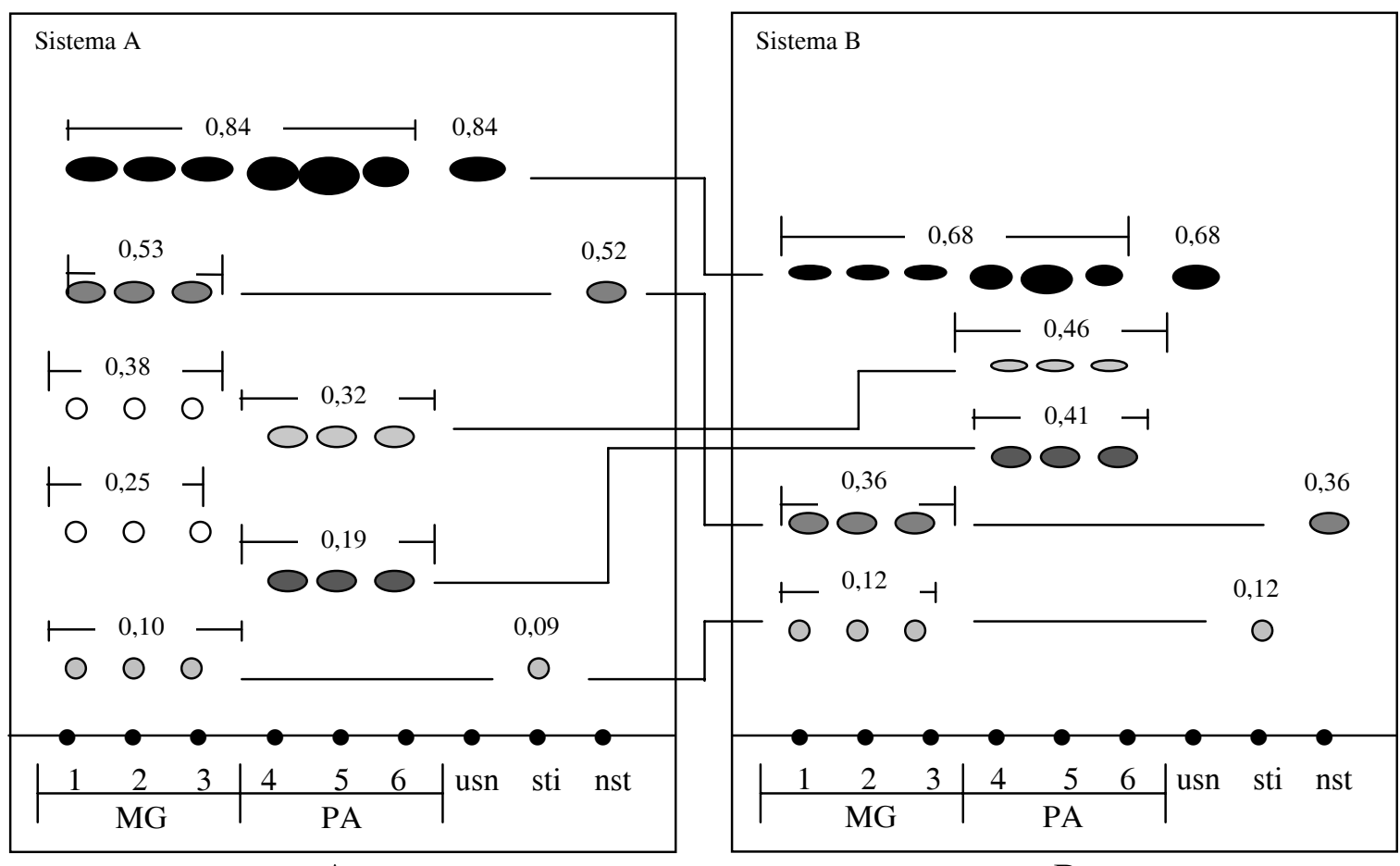

A

B

Figura 1. Cromatografia em camada delgada dos extratos orgânicos de Cladonia substellata Vainio. A. Cromatograma desenvolvido no sistema de solventes A (tolueno:dioxano:ácido acético 180:45:5 v/v). B. Cromatograma desenvolvido no sistema de solventes B (hexano:éter etílico:ácido fórmico 130:80:20 v/v). Extratos etéreo (1), clorofórmico (2) e acetônico (3) de C. substellata proveniente de Minas Gerais (MG). Extratos etéreo (4), clorofórmico (5) e acetônico (6) de C. substellata proveniente do Pará (PA). usn = ácido úsnico; sti = ácido estíctico; nst = ácido norestíctico.

Alguns autores, como Ahti (2000), referiram a ocorrência de várias substâncias, como ácidos graxos e terpenóides, ainda não identificados para esta espécie. Muitas vezes, as substâncias são sintetizadas em pequenas quantidades pelo talo liquênico, o que dificulta seu isolamento e sua identificação.

No presente trabalho foram detectadas substâncias que não puderam ser identificadas, por não coincidirem com nenhum dos padrões aplicados como referência nos testes cromatográficos, é o caso das bandas visualizadas no sistema A, com Rf igual a 0,38 e 0,25, na amostra de Minas Gerais, e 0,32 e 0,19, na amostra do Pará. As duas últimas apresentaram, respectivamente, $\mathrm{Rf}$ igual a 0,46 e 0,41 no sistema $\mathrm{B}$ (Fig. 1).

Embora tenham sido observadas variações quantitativas e qualitativas na composição química da espécie, uma das substâncias esteve presente nas amostras de ambas as localidades, é o caso do ácido úsnico, que se apresentou em maior quantidade, como pode ser observado pelo tamanho das bandas cromatográficas visualizadas na Fig. 1. Esses dados estão de acordo com Pereira et al. (1991), que encontraram cerca de $90 \%$ de ácido úsnico em C. substellata proveniente de Santa Rita, PB, Brasil.

Os testes antimicrobianos demonstraram que os extratos de $C$. substellata proveniente do Estado do Pará foram inativos contra todos os fungos testados, entretanto os extratos etéreo e clorofórmico da amostra de Minas Gerais apresentaram atividade contra Trichophyton tonsurans, T. rubrum, T. mentagrophytes e Microsporum canis. Os demais dermatófitos e as leveduras foram resistentes a todos os extratos testados. Vale ressaltar que os extratos da amostra proveniente de Minas Gerais, que foram ativos contra fungos, apresentaram inibição apenas na concentração de $1 \mathrm{mg} / \mathrm{mL}$, demonstrando a menor sensibilidade desses microrganismos às substâncias liquênicas (Tab. 1).

Hale (1974) conferiu propriedade antifúngica às substâncias liquênicas, atribuindo aos ácidos úsnico e haematômico a capacidade de inibir Neurospora crassa. Moderado grau de inibição foi atribuído também aos ácidos vulpínico, salazínico e úsnico frente ao fungo Trichosporium. Díaz et al. (1988) testaram a atividade da l-cloropannarina contra diversos grupos 
Tabela 1. Atividade antimicrobiana dos extratos orgânicos das amostras de Cladonia substellata Vainio provenientes dos Estados de Minas Gerais e Pará, Brasil.

\begin{tabular}{|c|c|c|c|c|c|c|c|c|c|c|c|c|c|c|c|c|c|c|}
\hline \multirow{4}{*}{ Microrganismos } & \multicolumn{9}{|c|}{ Minas Gerais } & \multicolumn{9}{|c|}{ Pará } \\
\hline & \multicolumn{18}{|c|}{ Extratos $(\mathrm{mg} / \mathrm{mL}) /$ Halos de inibição $(\mathrm{mm} \phi)$} \\
\hline & \multicolumn{3}{|c|}{ Etéreo } & \multicolumn{3}{|c|}{ Clorofórmico } & \multicolumn{3}{|c|}{ Acetônico } & \multicolumn{3}{|c|}{ Etéreo } & \multicolumn{3}{|c|}{ Clorofórmico } & \multicolumn{3}{|c|}{ Acetônico } \\
\hline & 1 & 0,1 & 0,01 & 1 & 0,1 & 0,01 & 1 & 0,1 & 0,01 & 1 & 0,1 & 0,01 & 1 & 0,1 & 0,01 & 1 & 0,1 & 0,01 \\
\hline \multicolumn{19}{|l|}{ Bactérias } \\
\hline Bacillus subtilis & 17 & 8 & - & 17 & 7 & - & 11 & 7 & - & 15 & 12 & - & 14 & 11 & - & 14 & 8 & - \\
\hline Staphylococcus aureus & 12 & 9 & - & 13 & 10 & - & 13 & 9 & - & 12 & 8 & - & 13 & 10 & - & 11 & 8 & - \\
\hline Pseudomonas aeruginosa & - & - & - & - & - & - & - & - & - & - & - & - & - & - & - & - & - & - \\
\hline Escherichia coli & - & - & - & - & - & - & - & - & - & - & - & - & - & - & - & - & - & - \\
\hline Klebsiella pneumoniae & - & - & - & - & - & - & - & - & - & - & - & - & - & - & - & - & - & - \\
\hline $\begin{array}{l}\text { Xanthomonas campestris pv. } \\
\text { campestris }\end{array}$ & 28 & 21 & 17 & 35 & 29 & 20 & 32 & 24 & 17 & 30 & 23 & 15 & 36 & 31 & 24 & 21 & 16 & - \\
\hline $\begin{array}{l}\text { Xanthomonas campestris pv. } \\
\text { vesicatoria }\end{array}$ & 28 & 18 & 12 & 32 & 22 & 16 & 26 & 19 & 12 & 24 & 15 & - & 30 & 21 & 15 & 20 & 13 & - \\
\hline Ralstonia solanacearum bv. I & 25 & 20 & 12 & 25 & 18 & 9 & 25 & 12 & - & 27 & 20 & 10 & 25 & 23 & 13 & 20 & 19 & 10 \\
\hline Ralstonia solanacearum bv. III & - & - & - & - & - & - & - & - & - & - & - & - & - & - & - & - & - & - \\
\hline \multicolumn{19}{|l|}{ Fungos } \\
\hline Trichophyton tonsurans & 10 & - & - & 8 & - & - & - & - & - & - & - & - & - & - & - & - & - & - \\
\hline Trichophyton rubrum & 14 & - & - & 7 & - & - & - & - & - & - & - & - & - & - & - & - & - & - \\
\hline Trichophyton mentagrophytes & 12 & - & - & 10 & - & - & - & - & - & - & - & - & - & - & - & - & - & - \\
\hline Trichophyton shoenlynii & - & - & - & - & - & - & - & - & - & - & - & - & - & - & - & - & - & - \\
\hline Epidermophyton floccosum & - & - & - & - & - & - & - & - & - & - & - & - & - & - & - & - & - & - \\
\hline Microsporum canis & 10 & - & - & 9 & - & - & - & - & - & - & - & - & - & - & - & - & - & - \\
\hline Candida albicans* & - & - & - & - & - & - & - & - & - & - & - & - & - & - & - & - & - & - \\
\hline
\end{tabular}

*Duas cepas (isolados clínicos n. 6307 e n. 6370).

de microrganismos e encontraram maior resistência de fungos filamentosos e leveduras. No presente trabalho, os extratos de C. substellata de ambas as localidades foram ineficazes contra as duas cepas de Candida albicans, concordando com os dados de Silva et al. (1986) e Xavier Filho et al. (1987), que demonstraram a resistência de leveduras a substâncias produzidas por várias espécies de liquens. Da mesma forma, Harmala et al. (1992) observaram ineficácia do ácido úsnico frente a $C$. albicans até na concentração de $6 \mathrm{mg} / \mathrm{mL}$.

A maior sensibilidade de bactérias Gram positivas às substâncias liquênicas foi referida por vários pesquisadores, entre eles Bustinza (1951), Hawksworth \& Hill (1984) e Fahselt (1994). Segundo Díaz et al. (1988), bactérias Gram negativas como Escherichia coli e Klebsiella pneumoniae apresentaram resistência a l-cloropannarina, que se mostrou significativamente ativa contra bactérias Gram positivas, concordando com os dados de Hale (1983) que reportou a ineficácia dos ácidos úsnico e protoliquesterínico contra bactérias Gram negativas, como Escherichia, Salmonella e Shigella.
A Tab. 1 mostra que os extratos etéreo, clorofórmico e acetônico de $C$. substellata proveniente de Minas Gerais e Pará foram ativos contra Bacillus subtilis e Staphylococcus aureus (bactérias Gram positivas), na concentração de $1 \mathrm{mg} / \mathrm{mL}$ e $0,1 \mathrm{mg} / \mathrm{mL}$, e ineficazes frente a Escherichia coli, Klebsiella pneumoniae e Pseudomonas aeruginosa (bactérias Gram negativas), estando de acordo com os dados acima. Entretanto esses mesmos extratos apresentaram inibição contra Xanthomonas campestris pv. campestris, X. campestris pv. vesicatoria e Ralstonia solanacearum bv. I, todas bactérias fitopatógenas Gram negativas. As amostras de ambas as localidades foram ativas contra as mesmas espécies de bactérias, porém as fitopatógenas apresentaram maior sensibilidade, uma vez que foram inibidas inclusive na concentração de $0,01 \mathrm{mg} / \mathrm{mL}$, com exceção de Ralstonia solanacearum bv. III que se mostrou resistente a todos os extratos testados.

Das bactérias inibidas, $S$. aureus mostrou-se a menos sensível, concordando com os dados de Pereira et al. (1996), que encontraram ineficácia dos extratos brutos de C. substellata proveniente de Manaus, AM, 
Brasil, frente a esse microrganismo. Entretanto, Pereira et al. (1991) reportaram eficácia dos extratos de C. substellata procedente de Santa Rita, PB, Brasil, obtidos com diferentes solventes, frente a esse mesmo microrganismo, demonstrando que a capacidade de inibição varia em uma mesma espécie, dependendo da área de coleta e dos solventes empregados para extração, como referido por Ozturk \& Guvenc (1995) ao compararem a atividade antimicrobiana de Pseudevernia furfuracea coletada em diferentes regiões.

Os resultados obtidos com patógenos de plantas não puderam ser discutidos, porque não foram encontrados dados na literatura sobre a ação de substâncias liquênicas frente aos fitopatógenos aqui estudados. Vale salientar, porém, que Hale (1974) citou a inibição do vírus do mosáico do tabaco pelos ácidos úsnico e lecanórico, bem como de Corynebacterium michiganense pelo usnato de sódio, um sal obtido a partir do ácido úsnico. Além disso, testes in vivo demonstraram também a inibição de sintomas virais em quatro cultivares de Nicotiana tabacum (Stuebler \& Buchenauer 1996).

Os testes biocromatográficos foram realizados com os extratos clorofórmicos de ambas as amostras por terem apresentado maior efeito inibitório frente aos microrganismos testados, sendo selecionado Xanthomonas campestris pv. campestris, por mostrar-se o mais sensível. O biocromatograma revelou o ácido úsnico como princípio ativo da espécie, porém demonstrou que outras substâncias podem agir sinergicamente aumentando seu poder inibitório, como observado na amostra proveniente de Minas Gerais, que apesar de apresentar menor quantidade de ácido úsnico, revelou maior capacidade de inibição, o que se justifica pela ação sinérgica desta substância com o ácido norestíctico (Fig. 2).

Embora o biocromatograma tenha revelado ação sinérgica entre as substâncias encontradas na amostra de Minas Gerais, o ácido úsnico é, sem dúvida, a substância com maior poder inibitório, estando em maior concentração na amostra proveniente do Pará.

$\mathrm{O}$ teor (mg e \%) de cada extrato liquênico e o rendimento total de cada amostra de $C$. substellata estão apresentados na Tab. 2.

Segundo Fahselt (1994), os metabólitos secundários dos liquens constituem aproximadamente 0,1 a $5 \%$ do peso seco do talo liquênico, embora em alguns casos possam ser encontrados valores superiores. Neste trabalho observou-se maior rendimento da amostra proveniente de Minas Gerais,

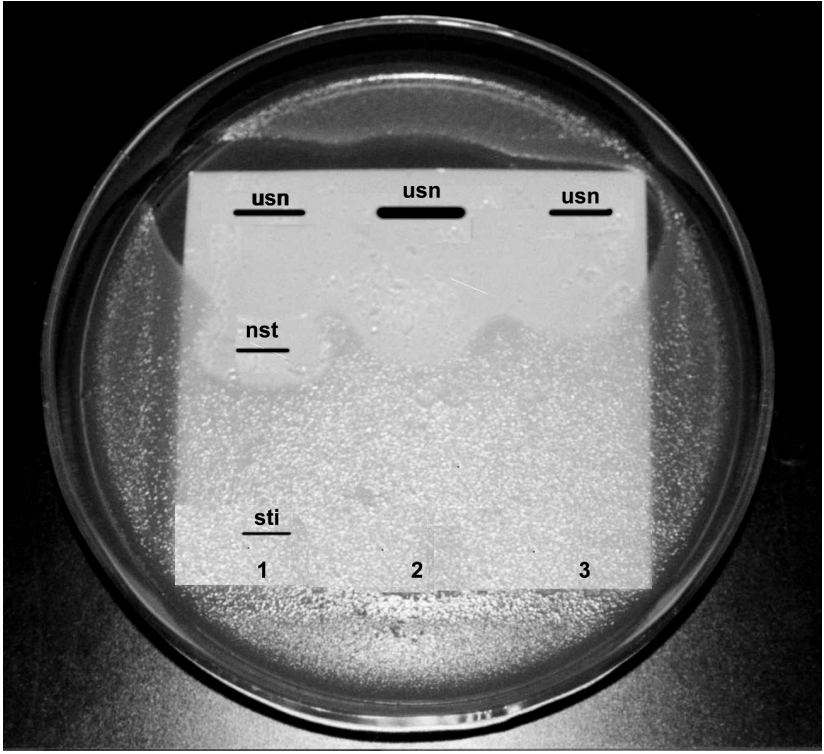

Figura 2. Biocromatograma do extrato clorofórmico das amostras de Cladonia substellata Vainio procedentes dos Estados de Minas Gerais e Pará, Brasil, revelando inibição sobre Xanthomonas campestris pv. campestris. 1. Amostra procedente de Minas Gerais, demonstrando o sinergismo entre os ácidos úsnico (usn) e norestíctico (nst) e a inatividade do ácido estíctico (sti). 2. Amostra procedente do Pará. 3. Ácido úsnico purificado.

atingindo aproximadamente $5 \%$ do peso seco do talo de C. substellata, enquanto a amostra do Pará rendeu $3,89 \%$. O extrato etéreo da amostra proveniente de Minas Gerais apresentou o maior rendimento, seguido pelo extrato acetônico, o que pode ser explicado, segundo Hale (1983), pela capacidade que esses solventes apresentam de extrair tanto os fenóis corticais como os medulares, enquanto outros solventes extraem apenas os fenóis de uma das camadas, como é o caso do clorofórmio. Entretanto, apesar do baixo rendimento do extrato clorofórmico na amostra de Minas Gerais, foi o que apresentou melhor inibição contra os microrganismos testados,

Tabela 2. Rendimento dos extratos orgânicos de Cladonia substellata Vainio procedente dos Estados de Minas Gerais e Pará, Brasil.

\begin{tabular}{lccccc}
\hline & \multicolumn{2}{c}{ Minas Gerais } & & \multicolumn{2}{c}{ Pará } \\
\cline { 2 - 3 } \cline { 5 - 6 } Extratos & \multicolumn{3}{c}{ Teores } \\
\cline { 2 - 4 } & $\mathrm{mg}$ & $\%$ & $\mathrm{mg}$ & $\%$ \\
\hline Etéreo & 594,8 & 2,97 & 141,2 & 0,71 \\
Clorofórmico & 146,1 & 0,73 & 415,5 & 2,08 \\
Acetônico & 264,9 & 1,32 & 220,5 & 1,10 \\
Rendimento total & 1005,8 & 5,02 & 777,2 & 3,89 \\
& & & & & \\
\hline
\end{tabular}


demonstrando ser o solvente mais eficaz na extração do princípio ativo desta espécie. O extrato clorofórmico da amostra do Pará também produziu maior inibição, além de apresentar maior rendimento, confirmando que o princípio ativo de $C$. substellata ocorreu em maior quantidade nesta amostra, como sugere a Fig. 1.

Segundo Asahina \& Shibata (1954) e Hale (1983), o ácido úsnico é uma substância de natureza cortical bastante solúvel em éter e clorofórmio, sugerindo que este metabólito esteja em maior teor nos extratos que contenham um desses solventes, o que explica a maior eficácia dos extratos etéreo e clorofórmico contra os microrganismos testados. O menor efeito inibitório do extrato acetônico justifica-se pela menor capacidade de extração do ácido úsnico, que é o metabólito ativo de $C$. substellata, como demonstrado nos testes biocromatográficos.

É importante considerar que o ácido úsnico é um dos metabólitos liquênicos mais conhecidos. Além da propriedade antibiótica, confere-se a ele várias outras propriedades biológicas, tais como antitumoral e antiinflamatória. Sugere-se que exerça também ação antimitótica, além de funcionar como indicador ambiental, uma vez que sua concentração varia de acordo com a presença de agentes tóxicos (Cardarelli et al. 1997; Cocchietto et al. 2002). Apesar da ampla utilização do ácido úsnico, sua toxicidade, os efeitos antiinflamatórios e seu mecanismo de ação ainda carecem de muitos estudos.

Cladonia substellata é uma espécie que produz ácido úsnico como resultado de seu metabolismo secundário, podendo ocorrer variações na sua concentração, dependendo de fatores como idade do talo, local e estação do ano em que a espécie for coletada, fatores genéticos, dentre outros. É importante ressaltar, também, que mais pesquisas se fazem necessárias na tentativa de se produzir grandes quantidades deste metabólito para utilizações futuras, sem destruição da biomassa liquênica.

\section{Agradecimentos}

Os autores são gratos ao Conselho Nacional de Desenvolvimento Científico e Tecnológico (CNPq) e à Fundação de Amparo à Ciência e Tecnologia do Estado de Pernambuco (FACEPE), pelo apoio financeiro; ao Dr. Marcelo P. Marcelli, do Instituto de Botânica, SP, pela identificação do material liquênico; à Dra. Rosa Lima Mariano, do Laboratório de
Fitossanidade da UFRPE, pelos fitopatógenos cedidos e pelas valiosas informações.

\section{Referências bibliográficas}

Ahti, T. 2000. Cladoniaceae. Flora Neotropica, Monograph 78. New York, Organization for Flora Neotropica, New York Botanical Garden.

Ahti, T.; Stenroos, S. \& Xavier Filho, L. 1993. The lichen family Cladoniaceae in Paraiba, Pernambuco and Sergipe, Northeast Brazil. Tropical Bryology 7: 55-70.

Asahina, Y. \& Shibata, S. 1954. Chemistry of lichen substances. Tokio, Japan Society for the Promotion of Science.

Bauer, A.W.; Kirby, W.M.M.; Sherris, J.C. \& Truck, M. 1966. Antibiotic Susceptibility Testing by a Standardized Single Disk Method. The American Journal of Clinical Pathology 45: 493-496.

Burkholder, P.R.; Evans, A.W.; McVeigh, I. \& Thornton, H.K. 1944. Antibiotic activity of lichens. Proceedings of the National Academy of Sciences 30: 250-255.

Bustinza, F. 1951. Contribuición al estudio de las propriedades antibacterianas y antifungicas del acido usnico e algunos de sus derivados. Annales del Instituto Botanico de A.J. Cavanilles 10: 157-175.

Cardarelli, M.; Serino, G.; Campanella, L.; Ercole, P.; Cicco Nardone, R.; Alesiani, O. \& Rossiello, F. 1997. Antimitotic effects of usnic acid on different biological systems. Cellular and Molecular Life Sciences 53: 667-672.

Cocchietto, M.; Skert, N.; Nimis, P.L. \& Sava, G. 2002. A review on usnic acid, an interesting natural compound. Naturwissenschaften 89: 137-146.

Culberson, C.F. 1972. Improved conditions and new data for the identification of lichen products by a standardized thinlayer-chromatographic method. Journal of Chromatography 72: 113-125.

Culberson, C.F.; Culberson, W.L. \& Johnson, A. 1983. Genetic and environmental effects on growth and production of secondary compounds in Cladonia cristatella. Biochemical Systematics and Ecology 11: 77-84.

Díaz, B.; Ugarte, R. \& Quilhot, W. 1988. Actividad antibacteriana in vitro de la depsidona clorada l'cloropannarina. Revista Latino-Americana de Microbiologia 30: 79-86.

Fahselt, D. 1994. Secondary biochemistry of lichens. Symbiosis 16: 117-165.

Grove, D.C. \& Randall, W.A. 1955. Assay methods, antibiotic activity: a laboratory manual. New York, Medical Enciclopedia.

Hale, M.E. 1974. The biology of lichens. London, Edward Arnold Pub.

Hale, M.E. 1983. The biology of lichens. London, Edward Arnold Pub.

Harmala, P.; Hiltunen, R.; Oksman-Caldentey, K.M.; Laasko, T. \& Kauppinen, V. 1992. Isolation and in vitro cultivation of lichen algae and their antimicrobial properties. Fitoterapia 63: 217-225. 
Hawksworth, D.L. \& Hill, D.J. 1984. The lichen forming fungi. New York, Chapman \& Hall.

Homans, A.L. \& Fuchs, A. 1970. Direct bioautography on thin layer, cromatograms as method for detecting fungitoxic substances. Journal of Cromatography 51: 327-329.

Huneck, S. 1999. The significance of lichens and their metabolites. Naturwissenschaften 86: 559-570.

Huovinen, K. 1985. Variation of lichen acids in Cladina stellaris and Cladina rangiferina in Finland and North Norway. Acta Pharmaceutica Fennica 94: 113-123.

Huovinen, K. \& Ahti, T. 1986. The composition and contents of aromatic lichen substances in the genus Cladonia. Annales Botanici Fennici 23: 173-188.

Muller, K. 2001. Pharmaceutically relevant metabolites from lichens. Applied Microbiology and Biotechnology 56: 9-16.

Ozturk, S. \& Guvenc, S. 1995. Comparasion of antimicrobial effects of lichen samples Pseudevernia furfuracea (L.) Zopf var. furfuracea which were collected from different regions. Turkish Journal of Botany 19: 145-148.

Pereira, E.C.; Silva, N.H.; Campos-Takaki, G.M.; Xavier Filho, L.; Legaz, M.E. \& Vicente, C. 1977. Antimicrobial activity of biologically-active compounds from lichen Cladonia crispatula. Boletim Ecotrópico - Ecossistemas tropicales 31: 9-19.
Pereira, E.C.; Silva, N.H.; Campos-Takaki, G.M.; Xavier Filho, L.; Legaz, M.E. \& Vicente, C. 1991. Fractionation of Cladonia substellata crude extracts and detection of antimicrobial activity. Boletim da Sociedade Broteriana 64: $173-186$.

Pereira, E.C.; Silva, N.H.; Brito, E.S.; Cruz, J. \& Silva, M.I. 1996. Atividade antimicrobiana de liquens amazônicos I: Cladonia corallifera e Cladonia substellata. Revista da Universidade do Amazonas, Série: Ciências Biológicas 1: 65-77.

Quilhot, W. \& Guzmán, G. 1988. Factores que determinan la variabilidad de las concentraciones de los metabolitos liquenicos. Revista Latinoamericana de Química 19: 19-22.

Silva, J.O.; Leite, J.E.M.; Paulo, M.Q. \& Xavier Filho, L. 1986. Atividade antimicrobiana de liquens brasileiros I. Boletim da Sociedade Broteriana 59: 87-96.

Stuebler, D. \& Buchenauer, H. 1996. Antiviral activity of the glucan lichenan (poly-beta-(1 fwdarw 3,1 fwdarw 4) D-anhydroglucose): 1. Biological activity in tabacco plants. Journal of Phytopatology 144: 37-43.

Xavier Filho, L.; Paulo, M.Q.; Leite, J.E. \& Silva, J.O. 1987. Atividade antimicrobiana de liquens brasileiros II. Boletim da Sociedade Broteriana 59(2): 79-86. 